\title{
DAS CHARGES PARA A LEITURA DE MUNDO: UMA REFLEXÃO DO ATO ÉTICO NAS CHARGES CHARLIE HEBDO
}

\author{
Claudia Maria Chiarion ${ }^{1}$ \\ Cláudia Meire Rodrigues ${ }^{2}$ \\ Eliana Vianna Brito Kozma ${ }^{3}$
}

\begin{abstract}
Resumo: O objetivo deste artigo, de caráter bibliográfico, tem como intuito propor reflexões à luz da teoria de Bakhtin sobre o ato ético no momento de produção das charges do jornal Charlie Hebdo. Veiculadas na mídia, as charges são gêneros cuja complexidade se configuram como um interessante objeto de análise para se observar como os sentidos se constroem no discurso, pois todo discurso é dialógico. As charges foram publicadas no dia 14-09-2015 no semanário francês Charlie Hebdo. A teoria que embasa essa pesquisa se refere aos conceitos bakhtinianos sobre o ato ético. $A$ análise mostra que os sentidos produzidos nos discursos permitiu verificar que a natureza do discurso da charge tem como estratégia a criticidade e que, para ser interpretada, exige que o leitor acione seus conhecimentos sobre fatos, contexto histórico e outros discursos, pois eles estabelecem relações dialógicas com outros contextos suscitando atitudes responsivas, responsáveis, reflexivas e éticas.
\end{abstract}

Palavras-chave: Charge; Conceitos backtinianos; Ato ético.

\footnotetext{
${ }^{1}$ Mestrado em Linguística Aplicada/UNITAU, Brasil E-mail:cmc_casteletti@hotmail.com.

2 Mestrado em Linguística Aplicada/UNITAU, Brasil E-mail: claudia.cmro@yahoo.com.br.

${ }^{3}$ Mestrado em Linguística Aplicada/UNITAU, Brasil E-mail: evbrito@uol.com.br.
} 